\title{
JNPH
}

Volume 5 No. 2 (Desember 2017)

(C) The Author(s) 2017

\section{APLIKASI TEORI KEPERAWATAN NOLA J PENDER PADA AN. R DALAM ASUHAN KEPERAWATAN DENGAN MASALAH SKABIES DI PUSKESMAS JEMBATAN KECIL}

\section{APPLICATION OF THERAPY THEORY NOLA J PENDER ON AN. R IN NURSING ASSURANCE WITH SCABIES PROBLEM IN JEMBATAN KECIL PUBLIC HEALTH CENTER}

\author{
ANITA MUTIARA \\ PUSKESMAS JEMBATAN KECIL KOTA BENGKULU \\ Email: anita.mwsia@gmail.com
}

\begin{abstract}
ABSTRAK
Salah satu faktor pendukung terjadinya penyakit skabies adalah sanitasi yang buruk dan dapat menyerang manusia yang hidup secara berkelompok, yang tinggal di asrama, barak-barak tentara, rumah tahanan, dan pesantren maupun panti asuhan (Badri, 2008).Usaha penyehatan lingkungan merupakan suatu pencegahan terhadap berbagai kondisi yang mungkin dapat menimbulkan penyakit dan sanitasi merupakan faktor yang utama yang harus diperhatikan. Keperawatan sebagai pelayanan professional, dalam aplikasinya harus dilandasi oleh dasar keilmuan keperawatan yang kokoh, dengan demikian perawat harus mampu berfikir logis dan kritis dalam menelaah dan mengidentifikasi fenomena respon manusia. Banyak bentuk bentuk pengetahuan dan keterampilan berfikir kritis harus dilakukan pada setiap situasi klien, antara lain dengan menggunakan model-model keperawatan dalam praktik keperawatan sesuai dengan kebutuhan. Dari beberapa model konsep, salah satu diantaranya adalah teori model keperawatan nola $\mathrm{j}$ pender, model promosi kesehatan ini merupakan sebuah teori yang menggabungkan 2 teori yaitu Teori Nilai Harapan (Expectancy value) dan Teori Kognitif Social (Social Cognitive). Teori Pender tentang model promosi kesehatan ini konsisten dan berfokus pada pentingnya promosi dan pencegahan kesehatan untuk dilakukan guna peningkatan kesehatan klien atau masyarakat yang lebih baik dan optimal. Jenis studi kasus ini adalah studi kasus skabies dengan aplikasi teori Nola $J$ dengan menggunakan metode deskriptif yaitu suatu metode yang dilakukan dengan tujuan utama untuk membuat gambaran atau deskripsi tentang suatu keadaan secara obyektif dan memusatkan perhatian pada objek tertentu. Hasil penelitian didapatkan keefektifan dari teori Nola $\mathrm{j}$ pender pada masalah skabies ini yaitu mengajarkan pada pasien Resiko Penularan Penyakit dengan penggunaan barang secara bersamaan atau bergantian sesama teman di asrama yang di tempatinya sehingga terhindar dari komplikasi dengan tentunya melaksanakan implementasi yang telah diberikan dengan mengacu pada pelaksanaan hidup bersih dan sehat serta pengaturan pola makanan yang tidak boleh di konsumsi oleh an.R, dimana pelaksanaan tindakan dilakukan selama 5 hari semua implementasi dapat di pahami dan dilakukan sesuai dengan teori Nola j pender yang berfokus pada perawatan pasien dalam memelihara kesehatan dan teori ini bisa diterapkan langsung dengan kasus pasien skabies. Disarankan pada perawat agar lebih memperhatikan pasiennya serta diharapkan pada perawat untuk memanfaatkan fasilitas kesehatan yang ada untuk memantau perkembangan pasien atau memecahkan masalah kesehatan yang ada pada pasien.
\end{abstract}




\begin{abstract}
One of the factors supporting the occurrence of scabies disease is poor sanitation and can attack people who live in groups, living in dormitories, army barracks, prisons, and boarding schools or orphanages (Badri, 2008). Environmental health is a preventive measure against a variety of conditions that may cause illness and sanitation are the main factors that must be addressed. Nursing as a professional service, in its application must be based on a solid foundation of nursing science, so nurses must be able to think logically and critically in reviewing and identifying the phenomenon of human response. Many forms of knowledge and critical thinking skills should be done in every client situation, among others by using nursing models in nursing practice in accordance with needs. From several concept models, one of them is the nursing model model of Nola $\mathrm{j}$ pender, this health promotion model is a theory that combines two theories of Expectancy Value and Social Cognitive Theory. The pender theory of this health promotion model is consistent and focuses on the importance of health promotion and prevention to be done in order to improve the health of clients or communities better and more optimally. This type of case study is a case study of Scabies with the application of Nola J theory by using descriptive method that is a method done with the main purpose to create a picture or description of a situation objectively and concentrate on a particular object. The results of the research obtained effectiveness of the theory of Nola $j$ pender on the problem of this scabies is to teach the patient the risk of transmission of disease with the use of goods simultaneously or alternately fellow friends in the dorm in its place so avoid the complications with course implement the implementation that has been given with reference to the implementation of clean and healthy life and the regulation of food patterns that should not be consumed by an.R, where the implementation of the action is carried out for 5 days all the implementation can be understood and done in accordance with the theory Nola $\mathrm{j}$ pender which focuses on patient care in maintaining health and this theory can be applied directly with cases of scabies patients. It is advisable for Nurses to pay more attention to their patients and be expected to Nurses to take advantage of existing health facilities to monitor patient progress or solve existing health problems in patients
\end{abstract}

\title{
Keywords: Nola J Pender, scabies
}

\section{PENDAHULUAN}

Saat ini Badan Dunia menganggap penyakit skabies sebagai pengganggu dan perusak kesehatan yang tidak dapat dianggap lagi hanya sekedar penyakitnya orang miskin karena penyakit skabies masa kini telah merebak menjadi penyakit kosmopolit yang menyerang semua tingkat social (Agoes, 2009). Di beberapa negara termasuk Indonesia penyakit skabies yang hampir teratasi ini cenderung mulai bangkit dan merebak kembali. Selain itu, kasus-kasus baru berupa Skabies Norwegia telah pula dilaporkan, walaupun angka prevalensinya yang tepat belum ada, namun laporan dari dinas kesehatan dan para dokter praktek mengindikasikan bahwa penyakit skabies telah meningkat di beberapa daerah (Agoes, 2009). Menurut Departemen Kesehatan RI prevalensi skabies di Indonesia sebesar 4,60$12,95 \%$ dan skabies menduduki urutan ketiga dari 12 penyakit kulit tersering (Notobroto, 2005)

Kesehatan adalah keadaan sejahtera dari badan, jiwa, dan sosial yang memungkinkan setiap orang hidup produktif secara sosial dan ekonomis. Pembangunan kesehatan bertujuan untuk meningkatkan kesadaran, kemauan dan kemampuan hidup sehat bagi setiap orang agar terwujud derajat kesehatan masyarakat yang setinggi-tingginya. Kegiatan untuk 
meningkatkan kesehatan (promotif), mencegah penyakit (preventif), terapi (kuratif) maupun pemulihan kesehatan (rehabilitatif) adalah upaya kesehatan masyarakat (Depkes RI, 2010).

Standar Pelayanan Minimal (SPM), serta menurunkan angka kesakitan akibat penyakit menular (Depkes RI, 2010).Penyakit Skabies adalah salah satu penyakit kulit menular yang disebabkan oleh Sarcoptes scabei varian hominis.Penyakit ini dikenal juga dengan namathe itch, gudik atau gatal agogo (Harahap, 2010). Indonesia merupakan negara yang sedang berkembang, di mana pelayanan kesehatan masyarakatnya belum memadai sehubungan dengan adanya krisis ekonomi yang melanda Indonesia sejak tahun 1997. Permasalahan utama yang dihadapi masih didominasi oleh penyakit infeksi yang sebagian besarnya adalah penyakit menular yang berbasis lingkungan.Skabies ditemukan disemua negara dengan prevalensi yang bervariasi. Dibeberapa negara yang sedang berkembang prevalensi skabies sekitar 6\% $27 \%$ dari populasi umum (Sungkar, 2000).

Salah satu faktor pendukung terjadinya penyakit skabies adalah sanitasi yang buruk dan dapat menyerang manusia yang hidup secara berkelompok, yang tinggal di asrama, barak-barak tentara, rumah tahanan, dan pesantren maupun panti asuhan (Badri, 2008). Usaha penyehatan lingkungan merupakan suatu pencegahan terhadap berbagai kondisi yang mungkin dapat menimbulkan penyakit dan sanitasi merupakan faktor yang utama yang harus diperhatikan (Mukono, 2006).

Subchan (2001) menyatakan perilaku manusia sangat komplek dan mempunyai ruang lingkup yang sangat luas. Salah satu bentuk perilaku terhadap sakit dan penyakit yaitu bagaimana manusia bereaksi, baik secara pasif (mengetahui, bersikap, dan mempersepsi penyakit yang ada pada dirinya atau diluar dirinya) maupun aktif (tindakan atau praktik) yang dilakukan sehubungan dengan sakit maupun penyakit skabies. Terbentuknya perilaku bam dimulai dari pengetahuan yang kemudian menimbulkan respon batin dalam bentuk sikap yang akhirnya menimbulkan respon yang lebih jauh yaitu tindakan. Skabies merupakan salah satu penyakit yang sering diderita oleh anak pesantren. Anggapan ini disebabkan karena penyakit skabies selalu terjadi pada penghuni yang tidak pernah putus dan juga penyakit skabies ini sudah dianggap sebagai penyakit ringan.

Peningkatan kasus penyakit skabies yang meluas secara cepat, baik jumlah kasus maupun daerah terjangkit terutama di daerah yang padat penghuninya, seperti asrama, panti asuhan, pesantren, dan Lembaga Pemasyarakatan. Penularan penyakit skabies yang sangat cepat di lingkungan Lembaga Pemasyarakatan terutama disebabkan penyakit skabies merupakan penyakit yang dapat menular secara langsung dan juga disebabkan oleh perilaku penghuni yang kurang menjaga kebersihan diri.

Penyakit skabies yang terjadi di Lembaga Pemasyarakatan memberikan dampak kepada penghuni, terutama kepada penghuni lain yang baru menjadi warga binaan, karena kebiasaan warga binaan yang tidak baik dapat memberikan kerugian kepada warga binaan baru. Kegiatan-kegiatan penghuni pun menjadi terganggu, seperti kegiatan beribadah dan kegiatan lain yang telah diadakan oleh pihak lembaga pemasyarakatan.

Keperawatan sebagai pelayanan professional, dalam aplikasinya harus dilandasi oleh dasar keilmuan keperawatan yang kokoh, dengan demikian perawat harus mampu berfikir logis dan kritis dalam menelaah dan mengidentifikasi fenomena respon manusia. Banyak bentuk bentuk pengetahuan dan keterampilan berfikir kritis harus dilakukan pada setiap situasi klien, antara lain dengan menggunakan modelmodel keperawatan dalam praktik keperawatan sesuai dengan kebutuhan. Dari beberapa model konsep, salah satu diantaranya adalah teori model keperawatan Nola $\mathrm{j}$ pender, model promosi kesehatan ini merupakan sebuah teori yang menggabungkan 2 teori yaitu Teori Nilai Harapan (Expectancy value) dan Teori 
Kognitif Social (Social Cognitive). Teori Pender tentang model promosi kesehatan ini konsisten dan berfokus pada pentingnya promosi dan pencegahan kesehatan untuk dilakukan guna peningkatan kesehatan klien atau masyarakat yang lebih baik dan optimal.

Melihat hal di atas pada survei pendahuluan yang dilakukan di puskesmas jembatan kecil Bengkulu dari data pencatatan di puskesmas jembatan kecil kota Bengkulu jumlah yang terkena penyakit kulit secara keseluruhan didapatkan data bahwa pada tahun 2016, jumlah penderita adalah 57 orang dan pada tahun 2015 adalah sebanyak 144 orang.

\section{METODE PENELITIAN}

Jenis studi kasus ini adalah studi kasus Skabies dengan aplikasi teori Nola J Pender dengan menggunakan metode deskriptif yaitu suatu metode yang dilakukan dengan tujuan utama untuk membuat gambaran atau deskripsi tentang suatu keadaan secara obyektif dan memusatkan perhatian pada objek tertentu (Notoatmojo, 2010).

\section{HASIL PENELITIAN}

Aplikasi teori Nola J Pender dalam pemberian asuhan keperawatan pada pasien skabies. Dalam Bab ini, penulis akan membahas meliputi segi pengkajian, diagnosa, perencanaan keperawatan, implementasi keperawatan, dan evaluasi keperawatan mengenai kasus yang penulis angkat.

\section{Tahap Pengkajian}

Pengkajian adalah tahap awal untuk melakukan suatu asuhan keperawatan yang berguna untuk mengumpulkan data sebagai dasar untuk mengetahui kebutuhan klien sehingga dapat menentukan asuhan keperawatan yang akan di lakukan dalam pengumpulan data penulis menggunakan metode wawancara atau tanya jawab dengan pasien serta observasi dengan menggunakan pemeriksaan fisik. Selama melakukan pengkajian terhadap pasien, dalam studi penulis tidak banyak menemukan kesulitan dalam memperoleh identitas pasien, riwayat kesehatan pasien, demikian pula dengan data fisik yang penulis peroleh dalam observasi, pengkajian keperawatan dilakukan ini mengacu kepada teori Nola $\mathrm{j}$ pender, adapun hasil dari pengkajian pada pasien an.R sebagai berikut; Pengkajian perilaku sebelumnya meliputi pengalaman mengenai terjadinnya penyakit skabies. an.R belum pernah ada pengalaman tentang terjadinya penyakit skabies. an.R tidak mengetahui tentang pencegahan agar tidak terjadinya penyakit scabies, an.R selalu menggarut jika kulitnya terasa gatal. Pengkajian faktor personal meliputi faktor biologis (usia, jenis kelamin, indeks massa tubuh, status pubertas, kapasitas aerobik, kekuatan, kecerdasan, keseimbangan), faktor psikologis (harga diri, motivasi diri, kompetensi personal, status kesehatan sebelumnya, definisi tentang kesehatan) dan faktor sosial budaya (ras, etnik, penyesuaian diri, status sosial ekonomi). Usia an.R 15 tahun, tekanan darah 100/60 $\mathrm{mmHg}$, nadi 90x/menit, pernafasan $24 \mathrm{x} /$ menit, suhu $37^{\circ} \mathrm{C}$.

Keadaan umum lemah, penampilan rapi, gaya berjalan lordosis, Konjungtiva tidak anemis, sklera tidak ikterik, tidak ada gangguan penglihatan. Nafsu makan baik, 3x sehari dan minum susu, BAB 1x sehari, BAK 4-5 $\mathrm{x} /$ hari, an. $\mathrm{R}$ sulit untuk tidur karena adanya bintik merah dan gatal. Riwayat mimpi basah umur 13 tahun. An.R tinggal di asrama pesantren darussalam. Norma budaya menganut budaya jawa tetapi tidak diterapkan dalam semua sisi kehidupan. Keluarga saling menyayangi dan komunikasi berjalan dengan baik. An.R belum bekerja, pasien masih sekolah di MA kelas 1 An .R berasal dari keluarga yang kurang mampu ayah dan ibunya seorang petani yang pendapatannya tidak menetap. Pengkajian perilaku spesifik, pengetahuan dan sikap individu yang meliputi persepsi tentang manfaat tindakan, hambatan tindakan, kemampuan diri, aktivitas yang berhubungan dengan sikap, pengaruh 
interpersonal dan pengaruh situasional.

Keluarga memberi dukungan klien untuk kesembuhan klien, klien berharap sembuh dan bisa beraktifitas kembali, klien berharap mendapatkan obat untuk menghilangkan rasa gatal dan ruam kulit yang dialaminya. Muncul motif perilaku yang tidak sehat, pengurangan komitmen rencana kegiatan, kepuasan klien dalam perilaku yang tidak sehat, klien menggunakan barang secara bersamaan dan bergantian, ketidakpedulian klien terhadap kesehatannya klien tidak menggunakan fasilitas kesehatan yang ada.

Komitmen dan kosistensi klien dalam melaksanakan rencana kegiatan, klien termotivasi untuk berperilaku hidup sehat dan merubah pola hidup sehat, setelah melakukan aktivitas fisik, ada keinginan untuk hidup sehat setelah klien berusaha berubah supaya penyakit scabies, yang dialaminya bisa teratasi dan tidak sampai menyebabkan komplikasi. Keluarga, kelompok, dan pengaruh pelayanan kesehatan, norma dan model, serta keadaan lingkungan tempat klien berkumpul, teman - teman di sekeliling pasien sangat mempengaruhi faktor gaya hidup klien, keluarga dan teman - teman di sekeliling, klien berperan aktif dalam berhubungan/berinteraksi dengan klien, tidak ada panutan dari lingkungan dalam mencegah penyakitnya. Keluarga dan teman di sekeliling berperan aktif dalam berhubungan/ berinteraksi dengan klien, tidak ada panutan dari lingkungan dalam mencegah penyakitnya.

\section{Diagnosa Keperawatan}

Diagnosa keperawatan adalah penilaian klinik mengenai respon individu ,keluarga dan komunitas terhadap masalah kesehatan/proses kehidupan yang actual dan potensial . Masalah karakteristik dan pengalaman individual, Koping individu tidak efektif berhubungan dengan kurang pengetahuan mengenai pencegahan scabies, Gangguan pola tidur berhubungan dengan ketidaknyamanan pada kulit yang gatal, Masalah perilaku spesifik, pengetahuan dan sikap individu, Resiko penularan penyakit berhubungan dengan prilaku penggunaan barang secara bersama- sama.

\section{Intervensi Keperawatan}

Dalam penyusunan perencanaan keperawatan, penulis melakukan sesuai dengan diagnose yang telah di perioritaskan yaitu dengan komponen tujuan kriteria dan rencana keperawatan. Menurut Nola $j$ pender intervensi keperawatan yaitu proses kognitif yang mendasari diantaranya karakteristik dan pengalaman individual, perilaku spesifik, pengetahuan dan sikap individu.

\section{PEMBAHASAN}

\section{Implementasi Keperawatan}

Pada pelaksanaan tindakan keperawatan pada klien seluruh rencana tindakan dapat di aplikasikan dengan baik dan tidak ada masalah yang berarti. Karena banyak hal yang mendukung dan pelaksanaan asuhan keperawatan ini. Adapun faktor yang mendukung implementasi ini adalah semua masalah yang ada, penulis dapat melaksanakannya dan dari tindakan yang telah direncanakan dan diimplementasikan atas persetujuan pasien serta berdasarkan standar praktek keperawatan, karakteristik dan pengalaman individual.

Implementasi menurut Nola $\mathrm{j}$ pender terhadap diagnosa Koping individu tidak efektif yaitu dapat diatasi dengan mendiskusikan tentang pencegahan terjadinya penyakit scabies yaitu dengan cara menjaga pola hidup bersih dan sehat seperti ; mandi teratur dan menggunakan sabun, mencuci pakaian dan seprai tempat tidur minimal $2 \mathrm{x}$ dalam seminggu, kasur dan bantal di jemur minimal $2 x$ seminggu, tidak saling bertukar pakaian atau alat mandi dengan orang lain,hindari kontak dengan orang yang di curigai terinfeksi penyakit scabies, diagnosa gangguan pola tidur berhubugan dengan ruam kulit dan gatal pada kulit, dapat di atasi dengan cara memberikan salap betametason 
pada pasien, dioleskan setelah mandi dan sebelum tidur, serta minum obat tablet yang diberikan perawat, agar gatal yang dirasakan berkurang sehingga pola istirahat dan tidur pasien tidak terganggu; perilaku spesifik, pengetahuan dan sikap individu; resiko penularan penyakit berhubungan dengan prilaku penggunaan barang secara bersamasama dapat diatasi dengan cara tidak menggunakan barang secara bersama- sama atau bergantian lagi dan selalu melakukan pola hidup bersih dan sehat.

\section{Evaluasi Keperawatan}

Evaluasi keperawatan adalah proses keperawatan mengukur respon klien terhadap tindakan keperawatan dan kemajuan klien kearah pencapaian tujuan ( potter dan perry 2006). Diagnosa yang penulis temukan ,semua sesuai dengan masalah yang di alami pasien an.R. klien mengerti dan memahami tentang pencegahan penyakit scabies, pasien sudah melakukan pola hidup bersih dan sehat dengan cara mandi teratur dan menggunakan sabun, mencuci pakaian dan seprai, membersihkan tempat tidur, kasur dan bantal di jemur, klien sudah melakukan pengobatan pada kulitnya sesuai yang dianjurkan perawat, klien tidak lagi menggunakan barang secara bersama- sama dan bergantian lagi.

\section{Keefektifan Teori Nola}

Keefektifan dari teori Nola $\mathrm{j}$ pender pada masalah scabies ini yaitu mengajarkan pada pasien Resiko Penularan Penyakit dengan penggunaan barang secara bersamaan atau bergatian sesama teman di asrama yang di tempatinya sehingga terhindar dari komplikasi dengan tentunya melaksanakan implementasi yang telah diberikan dengan mengacu pada pelaksanaan hidup bersih dan sehat serta pengaturan pola makanan yang tidak boleh di konsumsi oleh an.R, dimana pelaksanaan tindakan dilakukan selama 5 hari semua implementasi dapat di pahami dan di lakukan sesuai dengan teori Nola $\mathrm{j}$ pender yang berfokus pada perawatan pasien dalam memelihara kesehatan dan teori ini bisa di terapkan langsung dengan kasus pasien scabies.

\section{Kelebihan Teori Nola}

Keunggulan teori Nola $\mathrm{J}$ pender dalam pemeriksaan kasus scabies/kudis adalah di mana an.R mampu melakukan pola hidup bersih dan sehat dengan cara tidak menggunakan barang secara bersama - sama lagi seperti sabun, handuk dan pakaian serta mengetahui tata cara pengobatan penyakit scabies/kudis. Sehingga bisa terhindar dari penyakit serta komplikasinnya. Dimana teori Nola $\mathrm{j}$ pender ini berfokus pada pentingnya promosi kesehatan dan pencegahan penyakit adalah suatu hal logis dan ekonomis serta prilaku.

Pandangan teori Nola $\mathrm{j}$ pender ini, manusia mencoba menciptakan kondisi agar tetap hidup dimana mereka dapat mengekspresikan keunikannya. Manusia mempunyai kapasitas untuk merefleksikan kesadaran dirinya, termasuk penilaian terhadap kemampuannya. Manusia menilai perkembangan sebagai suatu nilai yang positif dan mencoba mencapai keseimbangan antara perubahan dan stabilitas. Setiap individu secara aktif berusaha mengatur perilakunya. Individu merupakan makhluk bio-psiko-sosial yang kompleks, berinteraksi dengan lingkungannya secara terus menerus, menjelmakan lingkungan yang diubah secara terus menerus. Profesional kesehatan merupakan bagian dari lingkungan interpersonal yang berpengaruh terhadap manusia sepanjang hidupnya. Pembentukan kembali konsep diri manusia dengan lingkungan adalah penting untuk perubahan perilaku.

Berdasarkan kebutuhan tersebut, Nola $\mathrm{j}$ pender memahami bahwa sikap yang berhubungan dengan aktivitas, komitmen pada rencana tindakan, dan adanya kebutuhan yang mendesak. Setiap manusia mempunyai karakteristik yang unik dan pengalaman yang dapat mempengaruhi tindakannya. Karakteristik individu atau aspek pengalaman 
dahulu lebih fleksibel sebagai variable karena lebih relevan pada perilaku kesehatan utama atau sasaran populasi utama seperti perilaku sebelumnya dan faktor personal. Manfaat tindakan secara langsung memotivasi perilaku dan tidak langsung mendetermin rencana kegiatan untuk mencapai manfaat sebagai hasil. Manfaat tadi menjadi gambaran mental positif atau reinforcement positif bagi perilaku. Menurut teori nilai ekspentansi motivasi penting untuk mewujudkan hasil seseorang dari pengalaman dahulu melalui pelajaran observasi dari orang lain dalam perilaku. Individu cenderung untuk menghabiskan waktu dan hartanya dalam beraktifitas untuk mendapat hasil yang potsitif. Keuntungan dari penampilan perilaku bisa intrinsik atau ekstrinsik.

\section{Kelemahan Teori Orem}

Kelemahan teori Nola $j$ pender ini menurut penulis adalah kurang lengkapnya point- point dalam pengkajian yang mencakup kajian tentang pasien dengan penyakit scabies secara spesifik, karena terlihat jelas aplikasi teori keperawatan ini hanya berfokus pada perawatan pasien yang sakit sehingga penulis sedikit kesulitan untuk menentukan diagnosa keperawatan prioritas.

\section{KESIMPULAN}

Intervensi dan implementasi yang ditegakkan oleh penulis sudah sesuai dengan teori Nola J sesuai diagnosa yang ditegakkan, implementasi dilakukan sesuai dengan rencana keperawatan yang disusun, disertai respon hasil dari pasien, tahap evaluasi dari diagnosa keperawatan yang penulis implementasikan selama 3 hari berhasil dilakukan, teori Model Roy efektif di aplikasikan pada pasien dengan kasus Scabies.

\section{SARAN}

Sebagai calon peneliti dan calon perawat profesional mampu untuk melaksanakan proses berfikir ilmiah terhadap kesenjangan yang ditemukan antara teori dan kasus sehingga akan meningkatkan mutu asuhan keperawatan yang profesional pada pasien dengan scabies serta perlu penanganan atau perawatan yang komprehensif pada pasien dan perlu pendidikan kesehatan pada pasien dengan scabies. Diharapkan kepada seluruh mahasiswa untuk lebih mendalami teori model keperawatan menurut Nola J. Pender sehingga dapat mengaplikasikan model ini dalam tatanan yang nyata di Puskesmas maupun asuhan Keperawatan Keluarga.

\section{DAFTAR PUSTAKA}

Brunner \& Suddarth, 2001, Buku Ajar Keperawatan Medikal Bedah, Edisi 8 Volume 2, Penerbit Buku Kedokteran EGC, Jakarta.

Dermawan, D., dan Rahayuningsih, T. 2010. Keperawatan Medikal Bedah Sistem Pencernaan. Yogyakarta: Gosyen Publishing.

Haryono, R. 2012. Keperawatan Medikal Bedah Kelainan Bawaan Sistem Pencernaan. Yogyakarta: Gosyen Publishing.

Lesti Elisa 2016 Aplikasi Teori Adaptasi Calista Roy dalam Pemberian ASKEP dengan Artritis Rematoid Kota Bengkulu

Liu, T., \& Campbell, A. 2011. Case Files Ilmu Bedah. Jakarta: Karisma Publishing Group.

Mansjoer, E, Doenges, 2012, Kapita Selekta Kedokteran. Edisi III, Jilid II, Penerbit Media Aesculapius FKUI, Jakarta.

Nanda. 2013. Diagnosis keperawatan: Definisi dan Klasifikasi. Jakarta: EGC.

Potter, P, A,. Perry, A., G. (2010). Fundamental Keperawatan: Konsep, Proses dan Praktik. Jakarta:EGC

Reksoprodjo, S. 2007. Kumpulan Kuliah Ilmu Bedah. Jakarta: Binarupa Aksara Publisher.

Roy S.C, Andrew H.A, The Roy Adaptation Model . The Defenitive Statement California : Appleton and Large 1991 
R.Sjamsuhidayat, 1997, Ajar Ilmu Bedah, Penerbit Buku Kedokteran EGC, Jakarta

Sjamsuhidajat \& Jong. 2010. Buku Ajar Ilmu Bedah. Jakarta: Buku Kedokteran EGC.Nursalam. (2010). Manajemen Keperawatan: Aplikasi dalam Praktik Keperawatan Professional

Sudarmi 2016 Aplikasi Teori Adaptasi Nola J dalam Pemberian ASKEP dengan Anemia pada Ny. E di RT 5 Rawa Makmur Kota Bengkulu

Zelyanti 2016.Teori Aplikasi Teori Adaptasi Nola J Dalam Pemberian ASKEP dengan Anemia pada Ny. P di RT 5 Rawa Makmur Kota Bengkulu 